\title{
TURISMO RURAL COMUNITARIO EN FRAILES DE DESAMPARADOS: PROPUESTA DE COMPETITIVIDAD Y PUESTA EN VALOR DE PRODUCTOS ENDÓGENOS CULTURALES
}

\author{
SUSAN SOLÍS ROSALES \\ Escuela de Ciencias Sociales y Humanidades \\ Universidad Estatal a Distancia, Costa Rica \\ ssolis@uned.ac.cr \\ ALONSO RODRÍGUEZ CHAVES \\ Escuela de Ciencias Sociales y Humanidades \\ Universidad Estatal a Distancia, Costa Rica \\ arodriguez@uned.ac.cr
}

\section{RESUMEN}

En el siglo pasado, el entorno rural dejó de ser escenario exclusivo de generación de alimentos y favoreció el desarrollo de otras actividades económicas como el turismo rural comunitario que reconoce y valora las especificidades patrimoniales de indole natural y cultural. En consideración, el escrito sobrepone el turismo como actividad económica, que bien aprovechada puede incrementar la competitividad de comunidades rurales. En esa dirección, señala, la necesidad de promover y sostener la estructura y la oferta productiva tradicional, aunado al conjunto de factores y recursos naturales y culturales disponibles como verdaderas ventajas. El planteamiento de la comunidad de Frailes en Costa Rica, de ofertar proyectos culturales productivos se percibe como experiencia potencial, dentro del marco de sostenibilidad e integralidad. En este caso, el uso de las capacidades endógenas culturales locales sirve de referente, puesto que la comunidad ha comprendido la necesidad de pertenecer a un sistema socio-organizacional conformado por vecinos con los que establecen relaciones para armonizar intereses y lograr aspiraciones comunes. En ese contexto, la adopción de estrategias empresariales convenidas por el colectivo favorece la promoción y expansión de actividades económicas nuevas; particularmente, para lograr competitividad y mejorar la calidad de vida de las zonas rurales.
PALABRAS CLAVE: TURISMO RURAL COMUNITARIO, PATRIMONIO CULTURAL, DESARROLLO RURAL, DESARROLLO SOSTENIBLE, COMPETITIVIDAD, CAPACIDADES ENDÓGENAS.

\section{ABSTRACT}

Last century saw a change in rural communities that moved from just being generators of agricultural products and food to become developers of other economic activities including rural tourism, an activity that values the specificities of natural and cultural patrimonies. This paper highlights tourism as an economic activity that, effectively oriented, can increase competitiveness in rural communities. It points to keep and promote traditional productive offers and structures and, as the same time, to consider available cultural and natural resources as real advantages. The case of Frailes, a community in Costa Rica that offers productive cultural projects, is seen as a highly potential experience related to sustainability and integrality. In this case, the use of local endogenous cultural capabilities works as a reference since the community has understood the need of being part of an organizational social system formed by neighbors that establish relationships to harmonize their interests and achieve common aspirations. In this context, the adoption of enterprising strategies agreed upon by the collective favors the promotion and expansion of new economic activities, mainly, to achieve competitiveness and to improve the quality of life in rural areas. 
KEYWORDS: COMMUNITY RURAL TOURISM, CULTURAL HERITAGE, RURAL DEVELOPMENT, SUSTAINABLE DEVELOPMENT, COMPETITIVENESS, ENDOGENOUS CAPABILITY.

\section{INTRODUCCIÓN}

La constante histórica presentada en los últimos siglos, identifica un endurecimiento de la significación cualitativa del medio rural; el cual fue asediado y relacionado con subdesarrollo, pobreza, atraso, entre un listón interminable de aseveraciones peyorativas.

Resultado de esas ideas, las zonas rurales se miraron despobladas y en un relativo abandono, con el consiguiente "desequilibrio territorial e infrautilización de los recursos naturales y culturales"; pues se creía que quien quería superarse, no tenía más remedio que huir de aquella "pesadilla" (Caldentey y Gómez, 2001).

En consecuencia, la ponderación de graves problemas estructurales que fueron aquejando a las comunidades rurales; conllevó a que el tema de la ruralidad retomara otro sentido a partir de segunda mitad del siglo recién pasado.

Particularmente, se enrumbó a establecer las bases del modelo que impulsa la revisión, análisis y articulación del tejido rural. En concreto, la ordenación del territorio y lógicas sectoriales de las actividades económicas que las constituyen (Proyecto Unidad Regional de Asistencia Técnica, 2006).

En resumen, en el ocaso de siglo XX se generó una reconceptualización, que hizo imprescindible el ordenamiento de los espacios rurales caracterizados por una identidad histórica y territorial homogénea derivada de la integración entre actividades agrícolas y otras de índole local. Así como la producción de bienes y servicios de particular especificidad, coherente con las tradiciones y las vocaciones naturales y territoriales (Ulate, 2005).
Consecuentemente, la nueva conceptualización permitió discernir disparidades y plantear la necesidad de diversificar y reformular la economía y el espacio rural dentro de un esquema integral-sostenible; ello por cuanto se suponía ayudaría a incrementar ganancias, mejorar y sistematizar prácticas de producción y preservar y conservar el ambiente y la cultura del entorno.

Dentro de ese entramado, Delgado y Ramos (2002) consideran que la actividad turística juega un papel crucial y sirve como herramienta que coadyuva a las comunidades rurales ha adquirir mayor reconocimiento y peso en el difícil proceso de comercialización. En mayor medida, se presenta como pieza clave en los esfuerzos emprendidos para dinamizar la economía y propiciar la transformación del sector productivo de zonas rurales.

En consideración, la idea que plantea el escrito es sobreponer la actividad turística como coadyuvante del desarrollo sostenible rural. Además, conocer experiencias turísticas iniciadas y desarrolladas en los últimos años, desde una perspectiva que aproxime comunidades rurales a situaciones de sostenibilidad y perdurabilidad de los valores naturales y culturales.

En general, se brinda atención especial a la experiencia inicial de turismo rural comunitario generada en el distrito de Frailes de Desamparados, específicamente el caso de la comunidad La Violeta, previendo que puede ser funcional a otras comunidades rurales, para competir y acceder con mejores ventajas comparativas según sus nichos de mercados.

Por lo anterior, el tema planteado trata de aportar nuevos conocimientos, debido a las implicaciones sociales, económicas y culturales que pueden causar la incorporación del turismo rural comunitario como instrumento de crecimiento para la economía rural. 


\section{ANTECEDENTES}

La comunidad de Frailes se encuentra ubicada a 28 kilómetros al sur del centro de San José, capital de Costa Rica. Según la Caja Costarricense del Seguro Social (CCSS) (2011), entidad que tiene a cargo la atención primaria de salud de la zona, Frailes cuenta aproximadamente con una población de 3437 habitantes, de los cuales 1737 son hombres y 1700 mujeres. Su extensión territorial aproximada es de $19,48 \mathrm{~km}^{2}$ con una densidad poblacional de $176,4 \mathrm{P} / \mathrm{Km}^{2}$.

La base económica del territorio es la producción agrícola, principalmente proveniente del café; razón por la que en épocas de recolección del cultivo llega una cantidad importante de trabajadores provenientes de otros lugares. El fenómeno inmigratorio llega acumular en cada temporada una población flotante de 600 personas, conformada en su mayoría por nicaragüenses e indígenas Ngobes, procedentes del sur del país (CCSS, 2011).

El lugar es montañoso y su núcleo poblacional más importante se asienta en una pequeña altiplanicie en las estribaciones de los cerros Bustamante. El resto del territorio son laderas prominentes con vertientes al río Candelaria y hacia el sur al río Tarrazú (Frailes de Desamparados, s.f.) A su vez se rigen bajo el concepto de la Cuenca Alta del río Candelaria siendo fundamental las actividades económicas y en general del territorio, debido a que, desde el punto de vista ambiental, puede repercutir ya sea positiva o negativamente en las comunidades que dependen del recurso hídrico para su vida cotidiana.
TABLA 1

\section{COSTA RICA: POBLACIÓN TOTAL POR PROVINCIA, CANTÓN Y DISTRITO}

\begin{tabular}{|c|c|c|c|}
\hline $\begin{array}{c}\text { Provincia, cantón } \\
\text { y distrito }\end{array}$ & Total & Urbano & Rural \\
\hline Costa Rica & 4301712 & 3130871 & 1170841 \\
\hline San José & 1404242 & 1213957 & 190285 \\
\hline Desamparados & 208411 & 194970 & 13441 \\
\hline San Miguel & 31805 & 30207 & 1598 \\
\hline Frailes & 3772 & 492 & 3280 \\
\hline Patarrá & 11921 & 10351 & 1570 \\
\hline San Cristobál & 3905 & 0 & 0 \\
\hline Rosario & 3088 & 0 & 0 \\
\hline
\end{tabular}

Fuente: Instituto Nacional de Estadísticas y Censos (INEC), 2011.

Frailes y comunidades aledañas como San Cristóbal y Rosario, son distritos del cantón de Desamparados, las cuales se caracterizan por su condición rural con fuertes lazos afectivos, históricos, culturales, productivos, entre otros. Son comunidades que por sus características rurales han tenido dificultades con los accesos a educación superior, problemas de infraestructura, así como de vinculación con las áreas urbanas.

Ante esa situación, las comunidades unificaron esfuerzos e impulsaron diferentes acciones que les han ido permitiendo dinamizar la economía, el territorio y las estructuras organizativas. Entre ellas, la creación e implementación de estrategias de diversificación de su economía, en las que destaca la articulación del desarrollo agrario y la actividad turística.

En dicho contexto, surgen incipientes alternativas de turismo rural comunitario que incentivan y apoyan la valoración e inclusión del conjunto de intereses, capacidades, tradiciones, entre otras expresiones culturales presentes en las comunidades rurales (Vattier, 2005). 
Estas cualidades se traducen en elementos de promoción de recursos locales, que anteriormente las poblaciones rurales desestimaban. En general, se percibe el uso de estas herramientas, desde el ámbito socioeconómico, como excelente maniobra para evitar la regresión económica, mantener la abundante obra campesina ocupada en labores propias del campo (Caldentey y Gómez, 2001).

\section{Descriptores}

Se abraza como hilo descriptor la visión de mundo rural, que sugiere un cambio de paradigma, de salir de sus desigualdades o falta de oportunidades, sin tener que acudir al tradicional asistencialismo oficial.

Es decir, un desarrollo rural entendido, dentro de un marco de gestión endógeno, que genere iniciativas desde de su propio conocimiento y organizaciones locales. Asimismo, con sentido integral; que crea complementariedades entre sectores y competitividad de las zonas rurales (Delgado y Ramos, 2002).

Sarraceno (2000) señala, la necesidad de promover y sostener, la estructura y la oferta productiva tradicional, manteniéndose el conjunto de factores, recursos disponibles y específicos de cada área como verdaderas ventajas.

En esa línea se desprende otro hilo descriptor, el Turismo Rural Comunitario, al estar íntimamente ligado a la reconceptualización de desarrollo rural; considerado además, motor coadyuvante para modernizar, diversificar e incrementar la competitividad de los sectores agroalimentarios tradicionales.

En ese sentido, el turismo constituye una alternativa económica para sectores de la población rural que requieren de nuevas fuentes de empleo, de ingresos complementarios. Es decir, que coadyuva a las comunidades rurales en la promoción de actividades agrícolas y no agrícolas, siendo grandes beneficiados aquellos segmentos de la población que no son capaces de migrar o que no están empleados (Riveros y Blanco, 2003).

Existe una tipología que básicamente determina las motivaciones que las personas tienen para realizar viajes, permitiendo con esta información identificar a los segmentos o nichos de mercados a los cuales van dirigidos los productos turísticos.

Entre los diversos tipos de turismo nos centraremos en el denominado turismo rural Comunitario que se ha afianzado en Costa Rica después de larga trayectoria de empresarios rurales y que en el caso particular de estudio es el que están implementando en su territorio.

El concepto definido en el país es el siguiente: "Experiencias turísticas planificadas e integradas sosteniblemente al medio ambiente y desarrolladas por los pobladores locales organizadas para el beneficio de la comunidad" según el Instituto Costarricense de Turismo y Alianza para el Fortalecimiento del Turismo Rural Comunitario.

Este tipo de turismo ha sido de importante surgimiento como forma de revalorización de los espacios rurales y medios de diversificar las economías locales. En Costa Rica, se ha impulsado a través de la política pública que insta a las instituciones del Estado a promover este tipo de turismo.

Siendo así, el turismo rural comunitario se establece como un cuarto macro producto de comercialización a nivel del país después del turismo naturaleza, playa y sol y aventura. 
Según la ley de Turismo Rural Comunitario en Costa Rica su objetivo principal es el fomento de la actividad turística por medio del impulso de empresas de base familiar y comunitaria.

En Latinoamérica ha sido interesantes las experiencias que amalgamaron el desarrollo de la actividad turística con la agricultura tradicional, utilizando la capacidad instalada ociosas de sus establecimientos (Román, 2009).

Se empezó a visualizar la actividad turística como una oportunidad para la generación de valor agregado a la producción agropecuaria. Siendo fundamental la articulación de servicios y productos conformando cadenas de valor e insertando elementos innovadores para la atracción y posicionamiento de destinos turísticos rurales.

Según lo expuesto, se plantea la siguiente interrogante, ¿Posee la comunidad de Frailes de Desamparados ventajas competitivas que le permita diversificar su economía; preservando sus expresiones culturales y características propias de su población?

Ante esa interrogante, cabe mencionar que la comunidad rural de Frailes mantiene particularidades y elementos potenciales, que pueden servir como insumos favorecedores de competitividad. Se percibe así, que la actividad turística ha comenzado a constituir un elemento dinamizador, que contribuye a dar prestigio y aprecio a los valores culturales originarios.

De esta manera, la demanda creciente de servicios al visitante, que encierran en sí mismos, la tradición y el espiritu rural del territorio crean el ambiente oportuno para estimular nuevas actividades económicas con peculiaridades territoriales.

\section{Actividad turística: estrategia de diversificación y valor agregado a la producción agropecuaria}

La dinámica de la actividad turística le permite a las familias campesinas o población de los territorios rurales ser parte de la generación de ingresos, principalmente si se promueve un tipo de turismo alternativo específicamente, el turismo rural comunitario. Cuando el visitante o turista pone en funcionamiento el sistema turístico, es decir, se traslada de su lugar habitual de residencia a un destino específico que cumpla con sus necesidades de recreación, esparcimiento, intercambio cultural, entre otros. Sin excepción se requerirá una gama de bienes y servicios para tener una estadía y traslado satisfactorio, de lo contrario no podría concretarse la experiencia turística.

Por lo tanto, se demandará insumos básicos y complementarios, principalmente los conformados por el patrimonio turístico; a saber la planta turística, infraestructura turística, superestructura turística y la materia prima denominada atractivos turísticos. Estos cuatro elementos deben ser parte de los encadenamientos de la actividad turística, para hacer efectiva la creación del producto turístico que estos espacios rurales visualizan desarrollar según sus posibilidades y expresiones culturales.

A continuación se presenta de forma graficada, la definición de cada componente del patrimonio turístico, con su respectiva caracterización para tener un panorama de la potencialidad de la comunidad de Frailes. 


\section{FIGURA 1}

\section{COMPONENTE DEL PATRIMONIO TURÍSTICO}

Atractivo Turístico: motivan y generan desplazamientos de los turistas. El territorio cuenta con atractivos naturales algunos espacios montañosos y ríos pero sobresalen especialmente los hechos históricos y expresiones culturales representadas en su cotidianidad así como las fincas cafetaleras (café orgánico), fiestas patronales, la Feria del Café, sus trapiches así como la amabilidad y calidez que caracteriza estas comunidades.
Planta Turística: encargada de atender y satisfacer los requerimientos del turista. Frailes no cuenta con servicios de hospedaje no obstante por desarrollar una modalidad de turismo rural comunitarios se han organizado familias para ofrecer el servicio de hospedaje además paulatinamente algunas familias han construido algunas cabañitas para alquilar. A futuro la organización de la Feria del Café tiene el proyecto de la creación del parque temático del Café por tanto será un importante insumo para el desarrollo de la actividad turística ene I territorio.

\section{Patrimonio Turístico Frailes}

Infraestructura Turística: hace referencia al conjunto de servicios básicos (generalmente de carácter público) necesarios para el funcionamiento de la planta turística y cuyos componentes son determinantes para la puesta en valor de los atractivos y para el desarrollo de la oferta. Al respecto Frailes tiene su debilidad en la señalización e información, insuficiencia de servicios de transporte, tratamiento de aguas negras, mal estado de sus caminos. Ente las fortalezas se tiene los servicios básicos incluido acceso a internet, múltiples vías de acceso, centros médicos, educativos, espacios de recreación.
Superestructura Turística: conformada por organismos públicos 0 privados que de forma directa 0 indirecta hacen posible el desarrollo de la actividad turística. El territorio se ha caracterizado por su nivel organizativo que como producto lograron tener representación en el gobierno lo cual como es la figura de vicealcalde, la unión de las asociaciones de desarrollo comunal, cuentan con grupo de protección de su recurso hídrico, grupo de mujeres en pro de generar beneficios a sus comunidades y más recientemente la creación de la Asociación de empresarios turísticos de la cuenta Alta del Río Candelaria.

Fuente: elaboración propia.

\section{Frailes: aspectos relevantes del territorio para el desarrollo de la competitividad}

Algunas reflexiones de Colom (1999) y Cordero (2006) apuntan que es sumamente valiosa la participación de todos los actores locales en la definición de la gestión y planificación de la actividad económica que quieren desarrollar en sus comunidades.

En consecuencia, la integración del conjunto de intereses presentes en las comunidades rurales son vitales, ello por cuanto favorece la cadena productiva y comercial; en nivel más externo, la reputación y calidad de los productos que se obtengan (Ablan, 2000).

A continuación se establece una breve aproximación de la competitividad potencial de la actividad turística desarrollada en Frailes según el caso de la comunidad la Violeta, localidad que cuenta con una población de 288 habitantes; para ello se abordaran aspectos internos y externos del territorio en mención (CCSS, 2011). 


\section{Vinculación de las expresiones culturales con actividades productivas}

En la actividad turística se tiene como insumo principal el desarrollo de atractivos turísticos. Siendo las expresiones culturales y hechos históricos atractivos importantes, ya que coadyuvan a dinamizar la economía local.

En las últimas décadas, los productos típicos han adquirido una fuerte carga simbólica. Al respecto se indica: "Valorizar los productos de nuestra tierra, es valorar también nuestros conocimientos técnicos y las riquezas portadoras de nuestras tradiciones y culturas" (Romero, 2005, p. 9).

Por consiguiente, la cultura se puede entender, como confluencia de elementos identitarios, de pertenencia y afiliación; que promocionados y valorizados de manera estratégica y responsable, sirven para diversificar la actividad económica de zonas rurales (Yúdice, 2002).

En razón, la actividad turística supone importantes medios para la puesta en valor de la cultura. Así, puede contribuir a gestionar y difundir los elementos propios de colectivos sociales ubicados en un territorio determinado. Para Riveros y Blanco (2003):

... se pueden considerar como expresiones que valoran la cultura del mundo rural, en el sentido, que también llevan asociado los recursos endógenos (paisaje, biodiversidad, emisión de oxígeno, permanencia de asentamientos humanos en zonas rurales, tradición, cultura) junto con la producción de bienes transables directamente (alimentos, bebidas, artesanías, cueros, confecciones, etc.) (p. 11).

En esa dirección, el planteamiento de algunas comunidades rurales de ofertar proyectos culturales productivos se percibe como factores potenciales, al ayudar al desarrollo económico dentro de principios de sostenibilidad e integralidad, en tanto apuntan a ser altamente beneficiosos, al proyectar y valorar el patrimonio cultural dentro de un marco de respeto a los métodos tradicionales de larga data (Ministerio de Agricultura Pesca y Alimentación, 1998).

En el caso de Frailes, la oferta de atractivos turísticos culturales se refiere al aprovechamiento de los paisajes rurales, tradiciones y costumbres campesinas relacionadas en demasía, con el cultivo del café. Producto agrícola, el cual ha constituido una importante función socioeconómica, pues históricamente, ha brindado ingresos a miles de pequeños productores agrícolas de toda la zona (Camacho y Roux, 1992).

La Feria del Café en Frailes, sirve de ejemplo, al articular agro con turismo. La actividad genera interesantes dinámicas y resultados económicos, asimismo, refuerza elementos de identidad regional y cultural (Caldentey y Gómez, 2001).

En general, en esta comunidad, los productores agrícolas ofrecen sus fincas como atractivos, donde no solo se descansa y se disfruta del paisaje rural, sino que se inserta al visitante, con la vida y cotidianeidad cultural. Como apunta Keegan (1997): "Los factores culturales son un reto para las empresas ya que están ocultos a la vista. La cultura es un comportamiento aprendido transmitido de generación en generación y resulta difícil para el forastero sin experiencia averiguarlo" (p. 107).

De este modo, destacan como alcance de la propuesta rural comunitaria, pequeñas experiencias familiares, que ofrecen a los visitantes la posibilidad de conocer modos de producción y de organización de fincas rurales. Se presenta un accionar lúdico-pedagógico, que divierte y educa, que entretiene y ofrece información sobre los procesos productivos, la historia y la cultura de comunidades rurales (La ruta dictada por el paladar, s.f.).

En general, la actividad turística en la zona de Frailes de Desamparados se ha visto como experiencias e iniciativas que buscan obtener la mejora de la calidad de vida de sus pobladores sin desvincularse de los rasgos identitarios, que les ha permitido diferenciarse de otros. 


\section{Calidades del visitante}

Resulta necesario determinar las calidades del turista esperado para dar paso a la innovación, desarrollar un producto y una comunicación efectiva que atraiga su atención (Solomon, 1997).

El turista o visitante, al dar sugerencias el empresario, tratará de satisfacerlo, claro está en la medida que se le permita según sus aspectos culturales, socioeconómicos y políticos.

Por otra parte, esta retroalimentación, establecerá una calidad estándar siendo muy relevante para una buena competencia, y para poder mantenerse satisfactoriamente en el mercado.

En el caso particular de Frailes, las calidades de quienes les visitan son principalmente, nacionales que se desplazan para disfrutar de su gente y demás atractivos turísticos. Así, aprovechan la relativa cercanía y corta distancia en que se encuentra la comunidad respecto al valle central del país.

Su promedio de estadía en forma general es de un un día, es decir regresan el mismo día a su lugar de origen. Los servicios requeridos básicamente son alimentos, bebidas, atracciones locales y, por supuesto, compartir la cultura reflejada por sus pobladores.

Debido a que la capacidad de hospedaje es limitada, las viviendas de la zona se involucran como proveedores de hospedaje, lo cual complementa los ingresos de las familias y evitan depender en un $100 \%$ de productos agrícolas. Lo que se espera es que estos servicios y otros que se ocupan, sean gestados y prestados en su totalidad por gente de la comunidad (Thual, 2004).

Esto puede servir como herramientas para que los vecinos de la localidad y poseedores del conocimiento tradicional se beneficien de manera equitativa. Con ello, no se monopoliza o se restringe la utilización comercial de los recursos a solo unas cuantas personas o familias.
Los miembros de estas comunidades enfatizan que su desarrollo turístico propenda por antonomasia, dentro de un marco sencillo, democrático, convenido, familiar, moral, que proteja y conserve el patrimonio cultural y natural. Para el colectivo, es claro que el conocimiento tradicional, símbolos y prácticas culturales propias de la comunidad son hereditarias y deben protegerse.

En esa dirección, pueden mantenerse siempre y cuando la mezcla de las características culturales continúe, y se tenga suficiente valor en el mercado para que los productores inviertan sus esfuerzos en mantener la integridad del indicador.

\section{Espacio organizacional}

La mayor representación que posee el territorio es de organizaciones productivas, de reciclaje, de ahorro y crédito, y muy recientemente la creación de la Asociación de Turismo Rural denominada CANDETUR y que ha permitido hacer nexos con diversas instancias en aras de insertarse en la actividad turística, así también aglomerando a los vecinos interesados en ser parte de este grupo heterogéneo que viene a conformar un producto de base comunal para sus visitantes. Es importante resaltar la organización de la Feria del Café que les ha permitido generar una plataforma de comercialización no solo del producto principal que es el café sino actividades alternativas como es el turismo.

En ese contexto, los emprendedores turísticos rurales han logrado desarrollar una cultura empresarial en la que cada vez más aprenden a insertarse sin temores en la alta competencia que impulsa el mercado nacional e internacional. Asimismo han comprendido la necesidad de pertenecer a un sistema socio-organizacional conformado por vecinos con los que establecen relaciones formales e informales, para armonizar intereses y dar cabida a un proyecto de aspiraciones comunes. 
Recientemente constituyeron la Asociación de Turismo Rural de Frailes para conjuntar esfuerzos en el proceso que están avocados a desarrollar en cuanto a la diversificación económica. De igual forma, se están realizando alianzas con el Centro Agrícola Cantonal, la Iglesia Católica, Universidades Públicas, Gobierno Local, entre otras instituciones públicas y privadas. Como señala Yúdice (2002): "La pertenencia cultural no solo se caracteriza por el conjunto de prácticas en que participa una comunidad específica, pues las relaciones con los otros y con las instituciones también demarcan el sentido de comunidad" (p. 77).

En la experiencia señalada, se entiende la cultura empresarial como un grupo de personas que han creado relaciones, que se transforma en conjunto social unitario y coherente para perseguir un fin, con sentido y eficacia. Además de constituirse la empresa como una unidad sociopolítica, ya que la unidad organizacional ha establecido relaciones de poder con otros agentes (Colom, Escardíbul, Saez y Cristóbal, 1999).

Por ende, no es extraño identificar el interés creciente de agrupaciones, concejos, asociaciones, cooperativas, entre otras organizaciones de productores, en acoger y desarrollar la actividad turística, para aprovechar capacidades, recursos y aspiraciones comunes (Martínez y Jiménez, s.f.).

El sistema simplemente registra y formaliza estas prácticas y las convierte en normas, pero incluso, las normas no son generalmente una imposición de un grupo determinado de la comunidad. Más bien, estas han nacido de la cercana y continua relación agrícola y familiar, igual de la alta conciencia de los vecinos de lo que quieren como turismo.

\section{Estrategias empresariales implementadas}

La adopción de estrategias empresariales favorece la promoción y expansión de actividades económicas nuevas; particularmente, para lograr competitividad y mejorar la calidad de vida de zonas rurales (Llorente, 2001).
Siendo así, resultan interesantes las estrategias utilizadas por la comunidad de Frailes, de manera principal, el uso de las capacidades endógenas locales, como elementos potenciales. Sin duda, constituye una experiencia valiosa, en que la aplicación del turismo está siendo más que positiva, puesto que ha servido para arraigar y retener su población en el medio y hacer crecer la renta de agricultores, ya que la mayoría de las iniciativas están siendo ligadas con el campesinado (Colom, Escardíbul, Saez y Cristóbal, 1999).

No obstante, pueblos rurales como el mencionado, constituyen apenas una de las tantas localidades en que se puede evidenciar el "renacimiento rural", con el consecuente rescate de valiosos recursos territoriales, renovación y retención demográfica.

Para Ferrari (2008), la actividad turística no solo debe ser relacionada como herramienta pragmática, para que los pobladores puedan sobrevivir sino también, para coadyuvar a dar plusvalía a las tierras y desarrollar otras importantes actividades económicas.

Aún a sabiendas del coste aumentado en la implantación, el balance final beneficio-coste es favorable, contribuyendo con nuevas inversiones a la búsqueda del equilibrio entre territorios, aumento del nivel de vida y desarrollo de tales zonas. En ese sentido, el mismo autor señala que las estrategias emprendidas hacen de las comunidades rurales más codiciadas y aptas para invertir en ella (Ferrari, 2008).

Por consiguiente, el turismo se ha convertido en una estrategia altamente favorecedora, para la proliferación de empresas gestoras de nuevos proyectos y la redistribución de la actividad económica, objetivos que han repercutido positivamente, en el desarrollo económico de zonas rurales.

Por tanto, el turismo significa un concepto integral de trascendencia, al constituir un valioso instrumento para el desarrollo de la economía, 
pues tiene por objeto la "promoción colectiva", ya que en muchos casos, son fruto de la relación estrecha entre grupos humanos y la tierra de donde provienen (Comisión Europea, 2006)

Para los pobladores, el uso del turismo se puede traducir en elementos de promoción, valorización de recursos locales, estrategia de desarrollo rural y una plataforma de apoyo para empresas pequeñas y medianas locales; ello no necesariamente lo es para grandes firmas transnacionales, las cuales por su desarraigo pueden verter sus intereses en solo ganancias económicas.

De conformidad con lo anterior, varios especialistas nacionales de la talla de Barquero (2003) y Cordero (2006) insisten en recomendar que sean las comunidades rurales las que gestionen, por iniciativa propia, la actividad turística. Por lo tanto, los contactos e injerencia de grupos externos en el proceso deben ser vistos con sigilo y recelo, pues la actividad puede ser afectada ante la ofensiva de intereses enajenados.

No obstante, la integración de la población de Frailes es un elemento fundamental, de no ser así, sería muy difícil la defensa y promoción del producto turístico de forma aislada e individual, razón que supera el ámbito de lo meramente económico, para entroncar con aspectos socioculturales (Ministerio de agricultura, alimentación y medio ambiente de España, s.f, p. 13).

Actualmente, líderes y vecinos de la comunidad de Frailes, han estado desarrollando la Feria del Café que a lo largo de seis años aproximadamente, les permitió posicionar este evento generando no solo capacidades empresariales sino reforzando sus valores de cooperación y solidaridad a nivel de la comunidad en aras de enfrentar los retos que conlleva iniciar una dinámica como la que ha alcanzado la Feria a nivel local, nacional e internacional.

En general, las agrupaciones comunales articulan jornadas de trabajo dedicadas a la discusión y comercialización, lo que conllevaba realizar actividades ordenadas en las comunidades (Llorente, 2001).
En este caso particular, la principal agrupación ha sido la Asociación de Empresarios Turísticos de la Cuenca Alta de la Candelaria, quienes convocaron a miembros de las comunidades del territorio que tuvieran el interés de insertarse en la actividad turística de forma directa o indirecta, y gracias a esa organización conjunta, han establecido alianzas estratégicas con universidades públicas, Gobierno Local, entre otros.

El Instituto Costarricense de Turismo (ICT), siendo el ente rector de la actividad turística a nivel nacional por parte del Estado costarricense, involucra en sus procesos de capacitación a la comunidad La Violeta mediante el proyecto de la Ruta etnocultural turística del 48; propuesta donde esta localidad participa activamente. Este aporte es fundamental para la mejora continua de las experiencias turísticas que la comunidad desea ofrecer a sus visitantes y turistas.

\section{CONCLUSIONES}

En el ocaso de siglo XX se generó un proceso revisionista de lo que se conocía como mundo rural. Consecuentemente, se hizo imprescindible el ordenamiento de los espacios rurales con la idea clara de diversificar y reformular su economía.

Dentro de ese contexto, surgen incipientes alternativas de turismo rural comunitario que incentivan y apoyan la valoración efectiva de conjunto de intereses, capacidades, tradiciones, entre otras expresiones culturales presentes en las comunidades rurales desde larga data.

En ese sentido, la actividad turística significa un concepto integral de trascendencia, al constituir un valioso instrumento para el desarrollo de la economía; ya que tienen por objeto la creación de complementariedades entre sectores y la "promoción colectiva", puesto que en muchos casos, son fruto de la relación estrecha entre grupos humanos y la tierra de donde provienen. 
Por consiguiente, el turismo se convierte en una estrategia altamente favorecedora, para la proliferación de empresas gestoras de nuevos proyectos y la redistribución de la actividad económica; objetivos que han repercutido positivamente, en el desarrollo económico de zonas rurales.

En razón, estas cualidades se traducen en elementos de promoción y en proyectos culturales productivos de importante potencial, que ayudan al desarrollo económico dentro de principios de sostenibilidad e integralidad. Pues, como recursos endógenos, apuntan a ser altamente beneficiosos, al proyectar y valorar el patrimonio cultural como grandes atractivos dentro de un marco de respeto a los métodos tradicionales.

En el caso de Frailes, la oferta de atractivos turísticos culturales se refiere al aprovechamiento de los paisajes rurales, tradiciones y costumbres campesinas relacionadas en demasía con el cultivo del café. Este producto agrícola ha constituido una vital función socioeconómica, al brindar ingresos a miles de pequeños productores agrícolas de toda la zona.

Así las cosas, resultan interesantes las estrategias utilizadas por esta comunidad, principalmente, el uso de las capacidades endógenas locales, como elementos potenciales. Sin duda, se han visto como experiencias e iniciativas que buscan obtener la mejora de la calidad de vida de sus pobladores sin desvincularse de los rasgos identitarios, que les ha permitido diferenciarse de otros.

Los miembros de estas comunidades enfatizan que su desarrollo turístico propenda por antonomasia, dentro de un marco convenido, familiar, que proteja y conserve el patrimonio cultural. Para el colectivo es claro, que el conocimiento tradicional, símbolos y prácticas culturales propias de la comunidad son hereditarias y deben protegerse.

En ese contexto, los emprendedores turísticos rurales han logrado desarrollar una cultura empresarial en la que cada vez más aprenden a insertarse en la alta competencia que impulsa el mercado actual.
Por ende, han comprendido la necesidad de pertenecer a un sistema socio-organizacional conformado por vecinos con los que establecen relaciones formales e informales, para armonizar intereses y dar cabida a un proyecto de aspiraciones comunes.

No obstante, la integración de la población de Frailes es un elemento fundamental. De no ser así, sería muy difícil la defensa y promoción del producto turístico de forma aislada, razón que supera el ámbito de lo meramente económico, para entroncar con aspectos socio-culturales.

Es interesante observar el avance que paulatinamente ha generado la comunidad La Violeta a través de la conjunción de sus vecinos para crear un pequeño conglomerado de emprendimientos turísticos, hecho que permite la distribución de tareas, para satisfacer las necesidades de los turistas o visitantes, bajo el marco de las posibilidades que comunidad puedan tener.

Esta articulación entre actores, ha ido transformando insumos físicos y de servicios en un producto terminado, por ende, esta relación ha sido estratégica y de gran valor, al lograr el beneficio mutuo.

\section{REFERENCIAS}

Ablan, E. (2000). Políticas de Calidad en el Sistema Agroalimentario Español. Agroalimentaria (10), pp. 63-72.

Ministerio de agricultura, alimentación y medio ambiente de España (s.f) Alimentos de España. Recuperado de http:// www.magrama.gob.es/es/alimentacion/temas/calidadagroalimentaria/calidad-diferenciada/dop/htm/reglamentacion.aspx

Banco Mundial, Proyecto Unidad Regional de Asistencia Técnica. (2006). Motores de crecimiento rural sostenible y reducción de la pobreza: el caso de Honduras. San José, Costa Rica: Proyecto Ruta.

Blanco, M. y Riveros, H. (2003). Documento Técnico: El Agroturismo, una Alternativa para Revalorizar la Agroindustria Rural como Mecanismo de Desarrollo Local. PRODAR: Lima, Perú.

Barquero, M. (30 de setiembre de 2003). Empresas "roban" las denominaciones geográficas: Pueblos procuran proteger sus marcas. La Nación. San José: Grupo Nación. 
Caja Costarricense del Seguro Social (CCSS). (2011). Balance Anual del Área de Salud: Coralillo-Frailes, 2010- 2011. Ebais Frailes de Desamparados.

Caldentey, A. y Gómez, A. (2001). Productos típicos y denominaciones: de la tutela a la divergencia. IV Coloquio hispano-portugués de estudios rurales. Actas del IV Coloquio Hispano-Portugués de Estudios Rurales. Universidad de Córdoba. Santiago de Compostela.

Camacho, C. y Roux, G. (1992). Caracterización de la cadena del caféen Guatemala. Recuperado de http://www.turismo20. com/profiles/blog/show?id=932414:BlogPost:27990

Colom, A., Escardíbul, B., Saez, E. y Cristóbal, E. (1999). Algunas reflexiones ante la evolución rural en el nuevo milenio. Desarrollo rural y nuevas políticas estructurales. Universidad de LLeida, Facultad de Veterinaria, Escuela Técnica Superior de Ingeniería Agraria y Universidad de Zaragoza.

Comisión Europea. (2006). Política de Desarrollo Rural 2007-2013. Agricultura y Desarrollo Rural. Recuperado de ec.europea. eu/agriculture/rurdev/index y Vinos y etnologías.

Cordero, A. (2006). Nuevos ejes de acumulación y naturaleza. El caso del Turismo. Buenos Aires: Consejo Latinoamericano de Ciencias Sociales.

Delgado, M. y Ramos, E. (2002). Understanding the evolution of the European Rural Policy: A methodological approach (Monografía de Investigación).

Delgado, M. (2001). Análisis de los efectos de la nueva política rural europea: una aplicación al caso andaluz. Tesis de Doctorado. Departamento de Economía Agrícola, Escuela Superior de Ingenieros Agrónomos y Montes, Universidad de Córdoba. Córdoba, España.

Delgado, M. y Ramos, E. (2002).The role of European Rural Development Programmes in Enhancing Democracy: The Case of Southern Spain. En A. Arzeni. R. Esspesti y F. Sotte. (Eds.). European Policy Experiences with Rural. Development Una publicación de Associazione Alessandro Bartola y European Association of Agricultural Economics. Kiel, KG.: Wissenschaftsvergag.

Ferrari, J. (2008). La cariñena una cepa buscando identidad: originaria de España es hoy día un vino que empieza a resurgir. Estilos de Vida, 2 (655), pp. 11-13

Frailes de Desamparados. (s.f). Recuperado de http://frailescr.com/frailes-de-desamparados

Instituto de Fomento y Asesoría Municipal. (1985). Atlas Cantonal de Costa Rica. Recuperado de http://ccp.ucr.ac.cr/bvp/ mapoteca/CostaRica/generales/atlas_cantonal_1984/

Instituto Nacional de Estadísticas y Censos. (2011). X Censo Nacional de Población. San José, Costa Rica.
Instituto Nacional de Estadísticas y Censos. (2011). VI Censo Nacional de Vivienda. San José, Costa Rica.

Keegan, W. (1997). Marketing Global. (5 ed.). Prentice Hall. Madrid, España.

Llorente, M. (2001). La fuerza de la diferencia: la denominación de origen, un instrumento para el desarrollo. Huesca, España: Ediciones La Val de Onsera.

Ministerio de Agricultura Pesca y Alimentación. (1998). Hechos y cifras del sector agroalimentario español. Área de documentación e información, Secretaría General Técnica. Madrid. España.

Martínez, M. y Jiménez, A. (s.f) La potenciación del origen en las estrategias de marketing de productos agroalimentarios. Universidad de Castilla-La Mancha y la Universidad Abierta de Cataluña. España.

Quesada, R. (2010). Elementos de Turismo. San José, Costa Rica: EUNED.

Román, F. y Ciccolella, M. (2009). Turismo Rural en Argentina. Buenos Aires: IICA.

Romero, A. (2005). Horchata ¿De chufa....? Recuperado de www.agroterra.com

Saraceno, E. (2000). La experiencia europea de desarrollo rural y su utilidad para el contexto latinoamericano. Taller sobre experiencias, políticas e instrumentos de desarrollo rural en los países latinos de Europa y América: un enfoque comparativo. San Fernando de Henares, Madrid, España.

Solomon, M. (1997). Comportamiento del consumidor. (3 ed.). México: Prentice Hall. p.126.

Thual, D. (2004). Denominaciones de Origen y marcas locales como medios para incrementar el valor local". Seminario Terra Madre. Recuperado en http://origin. technomind.be/fileadmin/origin/PDFs/Spanish/OriGIn_en_accion/Actividades_de_promocion/Seminarios_Conferencias/Abstract_Terra_Madre_Final.ES.

UNESCO. (2007). Un Museo Sostenible: museo y comunidad en la preservación activa del patrimonio. San José, Costa Rica.

Ulate, E. (2005). Breve Tratado de Derecho Agrario Comunitario e Internacional. Impresión Gráfica del Este. Tomo I y II. San José, Costa Rica. pp. 118 - 127.

Vattier, F. (2005). Las nuevas orientaciones normativas de la PAC y el desarrollo rural. La Rioja, España.

Yúdice, G. (2002). El recurso de la cultura (usos de la cultura en la era global). Barcelona: Editorial Gedisa.

Recibido: 11 de mayo de 2013 Aceptado: 23 de setiembre de 2013 